Mini Review

\title{
Proton magnetic resonance spectroscopy and its diagnostically important metabolites in the brain
}

\author{
Michal Bittšanský $y^{1}$, Desanka Výbohová ${ }^{2}$ and Dušan Dobrota ${ }^{1}$ \\ 1 Department of Medical Biochemistry, Jessenius Faculty of Medicine, Comenius University, Martin, Slovak Republic \\ 2 Department of Anatomy, Jessenius Faculty of Medicine, Comenius University, Martin, Slovak Republic
}

\begin{abstract}
This review provides a brief summary of the basic principles of proton magnetic resonance spectroscopy $\left({ }^{1} \mathrm{H}\right.$ MRS $)$ and its application in the human brain. We discuss the chemical structure, signal properties, biological function, normal spatial distribution and diagnostic potential of the most significant metabolites detectable in brain tissue: $\mathrm{N}$-acetylaspartate, $\mathrm{N}$-acetylaspartylglutamate, choline-containing substances, creatine, phosphocreatine, myo-inositol, glutamine and glutamate. We also present a few notes on the importance of proper spectral quantification and contemporary trends in ${ }^{1} \mathrm{H}$ MRS are presented.
\end{abstract}

Key words: Brain metabolites - Magnetic resonance spectroscopy

\begin{abstract}
Abbreviations: CSF, cerebrospinal fluid; GAMT, guanidinoacetate methyltransferase; GCP II, glutamate carboxypeptidase II; Gln, glutamine; Glu, glutamate; Glx, total signal of glutamine and glutamate; GPC, glycerophosphocholine; mGluR3, metabotropic glutamate receptor type $3 ;{ }^{1} \mathrm{H}$ MRS, proton magnetic resonance spectroscopy; $\mathrm{mI}$, myo-inositol; $\mathrm{MRI}$, magnetic resonance imaging; $\mathrm{MRS}$, magnetic resonance spectroscopy; NAA, N-acetylaspartate; NAAG, N-acetylaspartylglutamate; NMDAR, N-methyl-D-aspartate receptor; $\mathrm{PC}$, phosphocholine; $\mathrm{PCr}$, phosphocreatine; PRESS, point-resolved spin-echo sequence; tCho, "total choline"; tCre, "total creatine"; TE, echo time; TR, repetition time; SMIT, sodium/myo-inositol co-transporter; TGF $\beta$, transforming growth factor $\beta$; tNAA, "total NAA".
\end{abstract}

\section{Introduction}

Magnetic resonance spectroscopy (MRS) is a unique noninvasive method used in facilitating in vivo chemical assessment of brain tissue. It has been in use since the late 1970s (Chance et al. 1978). Following further development of its imaging modality (MRI) and widespread clinical MRI scanners, potential of MRS in diverse analysis of the human brain is being exploited more and more in areas of neurology, neurosurgery, oncology and psychiatry. The aim of this work is to summarize the basic principles of the most widespread form, proton magnetic resonance spectroscopy ( ${ }^{1} \mathrm{H}$ MRS), as well as its diagnostic role in the analysis of important ${ }^{1} \mathrm{H}$ MRS-detectable brain metabolites.

Correspondence to: Michal Bittšanský, Department of Medical Biochemistry, Jessenius Faculty of Medicine, Comenius University, Malá hora 4, 03601 Martin, Slovak Republic

E-mail: michal@bittsansky.net
After a brief description of the physical basis of ${ }^{1} \mathrm{H}$ MRS, our review focuses on the most important brain metabolites detectable with this method. We describe their chemical structure, signal properties, biological functions and normal distribution within the brain. We look at several significant examples of their pathologic alterations and conclude with a few remarks on spectral quantification and contemporary trends in ${ }^{1} \mathrm{H}$ MRS.

\section{Principles of ${ }^{1} \mathrm{H}$ MRS in the brain}

If a sample containing nuclei with non-zero magnetic moment $\left({ }^{1} \mathrm{H},{ }^{13} \mathrm{C},{ }^{31} \mathrm{P},{ }^{23} \mathrm{Na}\right)$ is present in a static magnetic field, $\mathrm{B}_{0}$, and we switch on a high-frequency oscillating magnetic field, $\mathrm{B}_{1}$, of a specific Larmor frequency and appropriate magnitude and duration, we can observe the nuclear magnetic resonance phenomenon. After switching off the external high-frequency field, the nuclei will induce a measurable oscillating voltage in the coil with Larmor frequency and decreasing intensity. 
Larmor frequency $v$ is defined for a certain type of nucleus and static magnetic field $B_{0}$ as $\nu=(\gamma / 2 \pi) \cdot B_{0}$, where $\gamma$ is the gyromagnetic constant of the nucleus (De Graaf 2007).

The motion of the electrons surrounding the nucleus creates a small, additional magnetic field in the close neighborhood of the nucleus. Since chemical bonds influence the electron orbitals, nuclei of the same element, but in different bonding configurations, will resonate at slightly different frequencies. MRS exploits this phenomenon to distinguish chemical substances from one another. To characterize resonating frequencies regardless of the static magnetic field, a quantity called chemical shift was introduced with the units "parts per million" (ppm) (De Graaf 2007).

In a typical ${ }^{1} \mathrm{H}$ short echo time magnetic resonance (MR) spectrum of a healthy brain tissue, four dominant low-molecular metabolite signals are apparent: $\mathrm{N}$-acetylaspartate (NAA), "total choline" (tCho), "total creatine" (tCre) and myo-inositol (mI) (Figure 1), together with a fifth broad sig- nal of total signal of glutamine and glutamate (Glx) at 2.1-2.4 ppm. The signal intensity of each metabolite, calculated as an area under the peak, is proportional to the number of resonating nuclei and is influenced by other factors, such as coil load and the relaxation times of the metabolites. A water signal (4.7 ppm), which has an intensity reaching thousands of times those of the metabolites, is usually suppressed and not displayed in the spectrum. A series of intense lipid peaks (a broad signal ranging from 0.9 to $1.3 \mathrm{ppm}$ ) can be observed in vivo, only in the spectra arising from tissues containing free lipids, such as subcutaneous fat and some tumors. Subcutaneous fat contribution can be minimized by proper localization of the spectrum outside these regions, or by suppression bands, which eliminate the lipid signals from the scalp.

In the measurement protocol, the echo time (TE) is the time taken, in milliseconds, for echo formation after the excitation pulse. As the MR signal of the metabolites decays with time, so, too, does the measured signal with increasing a

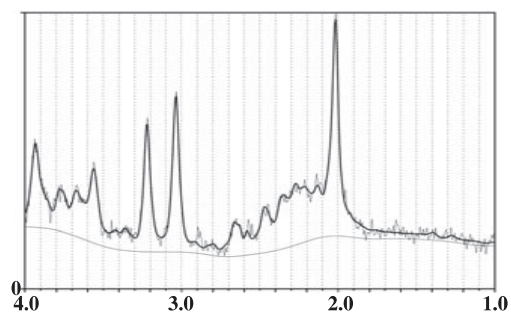

d

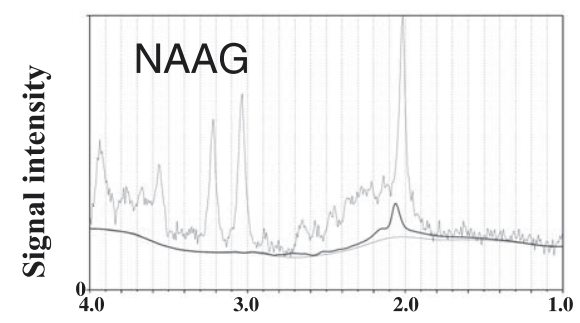

g

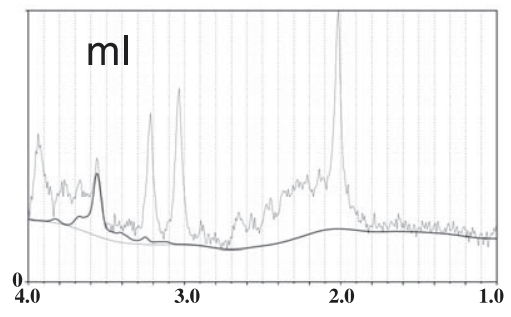

b

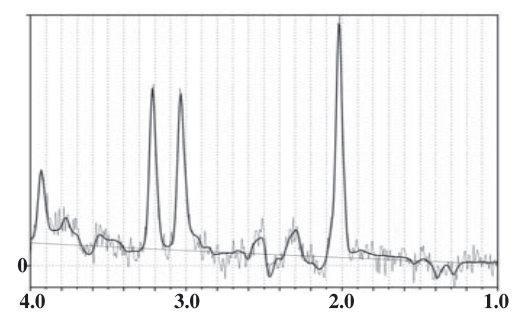

e

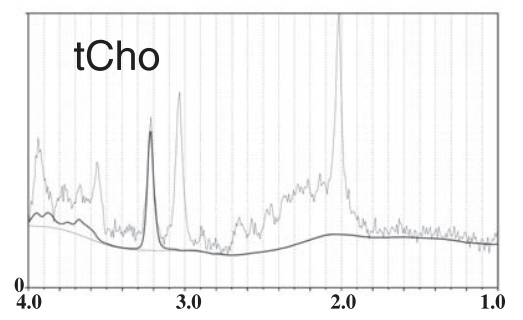

h

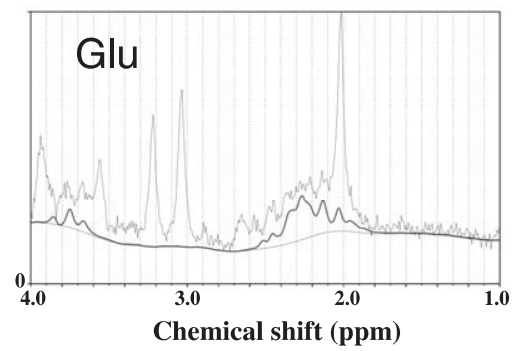

c

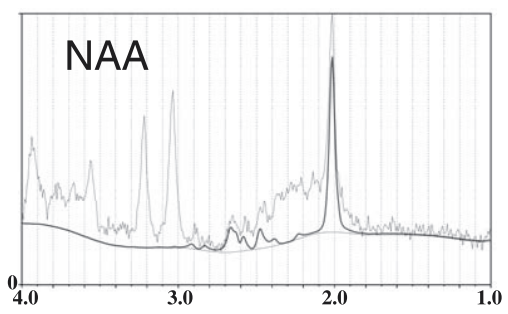

f

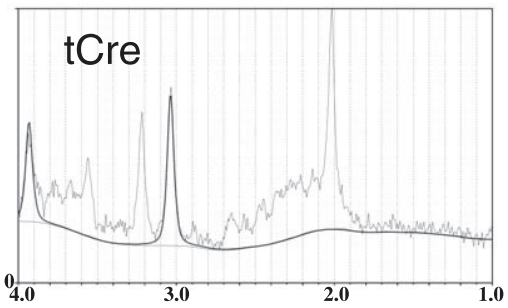

i

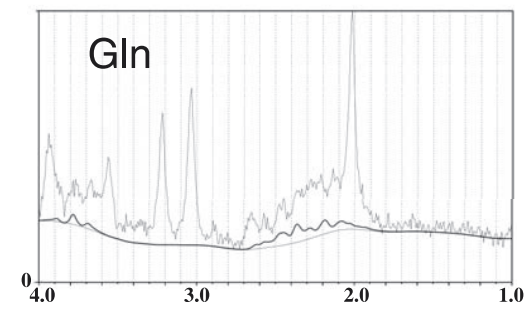

Figure 1. Examples of the LCModel results of in vivo proton MR spectra (1.5 T, PRESS, TR = $1500 \mathrm{~ms})$ measured with TE $=30 \mathrm{~ms}(\mathbf{a})$ and TE $=$ $135 \mathrm{~ms}$ (b), both from the same voxel localized in a healthy part of brain white matter of a patient with a glioma. The thick line is a mathematical fit of the measured spectrum. The spectrum (a) is decomposed using the LCModel to the main metabolite compounds: N-acetyl aspartate (NAA, main peak resonating at $2.01 \mathrm{ppm}, \mathbf{c}$ ), N-acetylaspartylglutamate (NAAG, $2.045 \mathrm{ppm}, \mathbf{d}$ ), "total choline" (tCho, $3.21 \mathrm{ppm}, \mathbf{e}$ ), "total creatine" (tCre, resonances at 3.03 and 3.93 ppm, f), myo-inositol (mI, $3.91 \mathrm{ppm}$, g), glutamate (Glu, h) and glutamine (Gln, i). 
TE. Spectral acquisition with a shorter TE (Figure 1a) has the advantages of higher metabolite signal, better visibility of the metabolites forming multiplets (e.g., mI, glutamate and glutamine) and more accurate correction of transverse relaxation time $\left(\mathrm{T}_{2}\right)$ values. The major disadvantage is baseline distortion. At longer TE (Figure 1b), signal intensities of metabolites decrease unequally due to different $\mathrm{T}_{2}$ values. In addition, spectral lines having multiplet structure become heavily distorted, complicating quantitative analysis.

There are three main groups of molecules based on their different behaviors in MRS. Firstly, signals from low-molecular compounds freely movable in the solution form high, distinct spectral peaks. Secondly, signals from rigid or bound macromolecules, such as the membrane phospholipids, are practically invisible. Thirdly, signals from non-rigid parts of macromolecules form broad peaks, especially in the short TE spectra (at longer TEs, these signals become extinct). This manifests as a wavy spectral baseline (represented by a thin line in the spectra; compare Figure 1a, b) and makes quantification of other metabolites difficult.

\section{Signals of the most important brain metabolites in vivo}

\section{$N$-acetylaspartate and $N$-acetylaspartylglutamate}

The highest ${ }^{1} \mathrm{H}$ MRS signal of a healthy adult brain comes from N-acetylaspartate (NAA) (Figure 1c). The main signal comes from the acetyl groups $\left(\mathrm{CH}_{3}\right)$ of NAA, which resonate with the chemical shift $2.01 \mathrm{ppm}$. There are also resonances of the $\mathrm{CH}_{2}$ groups as two double doublets with chemical shifts 2.5 and $2.7 \mathrm{ppm}$. At clinical magnetic fields measuring about 1.5 T, the signal of NAA is almost indistinguishable from the signal of $\mathrm{N}$-acetylaspartylglutamate (NAAG) (Figure 1d), with its main resonance frequency at 2.045 ppm (Frahm et al. 1991). Whereas many published papers deal with the NAA signal, in most cases a combined signal, tNAA (total NAA), consisting of NAA, NAAG and a small contribution from other similar molecules was measured. According to contemporary theories, NAAG is created from NAA, but its function and spatial localization is different from NAA (Figure 2). Therefore, we should bear

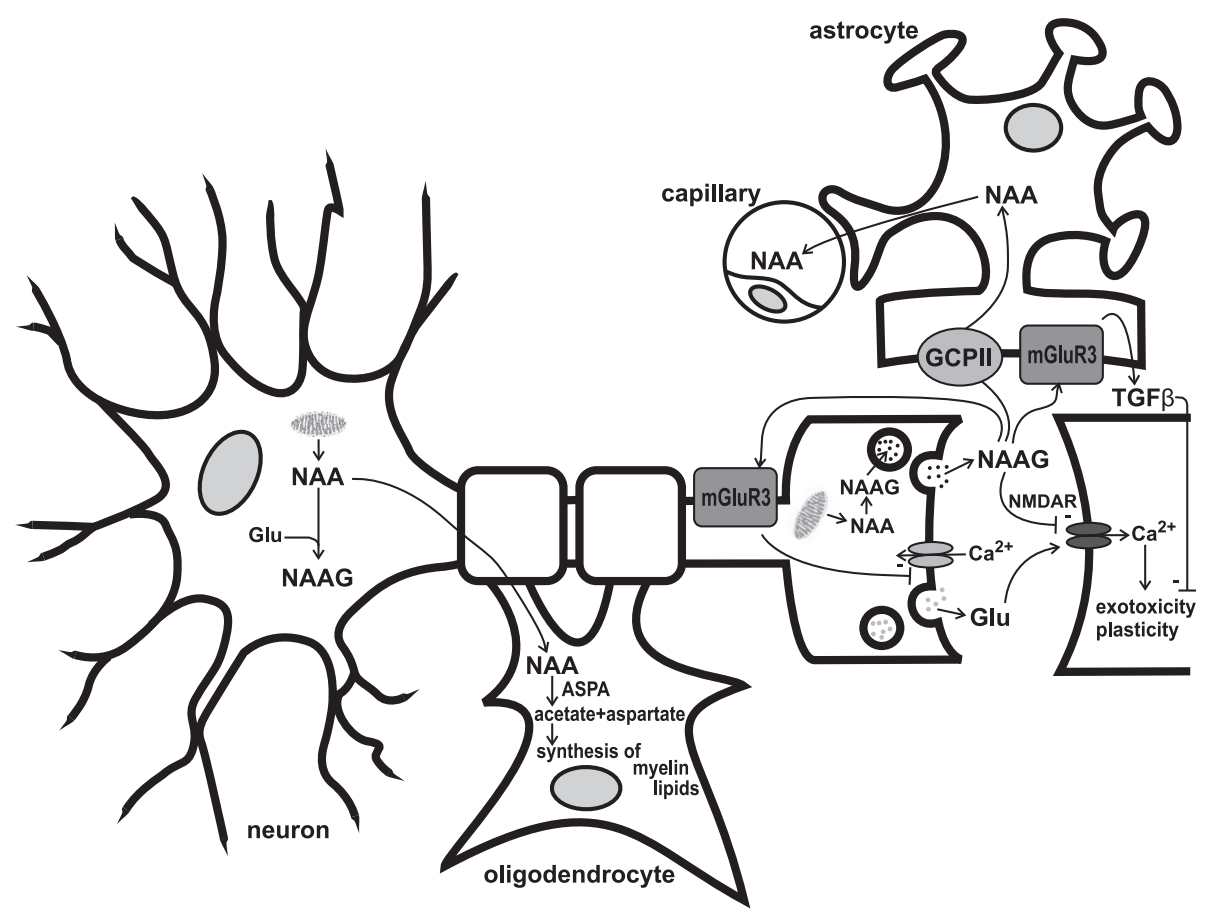

Figure 2. Interactions between neuronal and glial cells by means of $\mathrm{N}$-acetyl aspartate (NAA) and N-acetylaspartylglutamate (NAAG) (scheme was created according to Benarroch 2008). In neurons, NAA is synthesized in mitochondria and consequently transported to oligodendrocytes. There, it is metabolized by aspartoacylase to acetate. Acetate is a precursor for myelin lipid synthesis. In addition, NAAG is synthesized from NAA and glutamate in neurons, and then released from the synaptic vesicles acting as a co-transmitter, together with other neurotransmitters, such as L-glutamate. NAAG, acting by means of presynaptic metabotropic glutamate receptors type 3 (mGluR3), blocks the presynaptic $\mathrm{Ca}^{2+}$ channels and thereby inhibits the release of glutamate. NAAG can be bound to the N-methyl-D-aspartate receptors (NMDAR) and block their function. NAAG, acting by means of mGluR3 receptors in astrocytes, activates the release of transforming growth factor $\beta$, which can then contribute to its neuroprotective effects. After being released to the synapse, NAAG is hydrolyzed at the surface of astrocytes by glutamate carboxypeptidase II (GCP II) to form NAA and glutamate. Consequently, NAA is released from astrocytes to the overall circulation (Benarroch 2008). 
this in mind in any studies concerning primary observation of NAA.

Despite the fact that NAA is probably the most important detectable MR brain metabolite, little is known about its precise biochemical role in the brain. Although it is one of the most abundant amino acids of the central nervous system, this was not known until 1956. Its exact cellular localization was the subject of discussion until the 1990s, when studies using monoclonal and polyclonal antibodies revealed its distribution within the cells. It has been shown that NAA is present mainly in the neurons and their projections, but its concentration may differ according to the type of neurons (Simmons et al. 1991).

Theories about the biochemical role of NAA are still being discussed. It is suggested that NAA might be a storage substance for acetyl-CoA and aspartate, a regulator of protein synthesis, a source of the acetyl group for lipid synthesis, a catabolic product of NAAG (which is a neurotransmitter, in contrast to NAA) and an osmolyte (Moffett and Namboodiri 2006). Based upon the localization of anabolic and catabolic enzymes for NAA and NAAG, a theory of cyclic exchange of these substances and their intermediate products, such as acetate, aspartate, and glutamate, between neurons and glial cells was introduced as a mechanism of cell signaling. This theory is based on the findings that NAA and NAAG are synthesized predominantly in neurons, while their catabolic enzymes are localized in oligodendrocytes (for NAA) and astrocytes (for NAAG). According to this hypothesis, NAA is released from neurons as a signaling molecule for oligodendrocytes and NAAG for astrocytes (Baslow 2000). The theory is more clearly demonstrated in the diagram shown in Figure 2. The diagram summarizes the various theories about the roles of NAA and NAAG as signaling molecules for oligodendrocytes and astrocytes and their other metabolic pathways.

NAA and NAAG were mapped in the brain (Table 1). In a healthy brain, the concentration of NAA, calculated from in vivo MRS measurements with the most important corrections (see Table 1 for more details), reaches almost identical values of around $8.0-8.9 \mathrm{mmol} / \mathrm{l}$ in white and grey matter. In the occipital area with the visual cortex, however, values increased to more than $10 \mathrm{mmol} / \mathrm{l}$ (Pouwels and Frahm 1997). Spatial distribution of NAA in grey matter therefore correlates with the density of neuronal cells, which should be constant in the neocortex, with the exception of an increased concentration in the primary visual (occipital) area (Leuba and Garey 1989). Similar NAA signals in white matter show that NAA reaches high concentrations, not only in cell bodies and synapses, but also in axons (Pouwels and Frahm 1997). This result is in agreement with the results of previous immunohistochemical studies (Moffett et al. 1993).

In white brain matter, NAAG substantially contributes to the tNAA signal. However, quantification of NAAG in magnetic fields of up to $3 \mathrm{~T}$ is prone to substantial error. Therefore, only few publications deal with its concentration. Calculated concentrations of NAAG vary from $2.7 \mathrm{mmol} / \mathrm{l}$ in parietal and occipital areas to a significantly lower value of $1.5 \mathrm{mmol} / \mathrm{l}$ in the frontal grey matter. Its concentrations are

Table 1. Concentrations of the most important common metabolites in different parts of the brain, measured using proton MRS at $2.0 \mathrm{~T}$ (data from Pouwels and Frahm 1998)

\begin{tabular}{|c|c|c|c|c|c|c|c|c|c|c|}
\hline & \multicolumn{3}{|c|}{ White Matter } & \multicolumn{4}{|c|}{ Grey matter } & \multicolumn{2}{|c|}{ Cerebellum } & \multirow[b]{2}{*}{ Thalamus } \\
\hline & $\begin{array}{c}\text { Frontal } \\
\text { area }\end{array}$ & $\begin{array}{l}\text { Parietal } \\
\text { area }\end{array}$ & $\begin{array}{c}\text { Occipital } \\
\text { area }\end{array}$ & $\begin{array}{c}\text { Frontal } \\
\text { area }\end{array}$ & $\begin{array}{l}\text { Parietal } \\
\text { area }\end{array}$ & $\begin{array}{c}\text { Occipital } \\
\text { area }\end{array}$ & $\begin{array}{c}\text { Insular } \\
\text { area }\end{array}$ & $\begin{array}{l}\text { Hemi- } \\
\text { sphere }\end{array}$ & Vermis & \\
\hline tNAA & $9.6 \pm 1.1$ & $10.6 \pm 0.8$ & $10.4 \pm 0.9$ & $8.4 \pm 1.0$ & $8.7 \pm 0.8$ & $10.6 \pm 0.8$ & $9.6 \pm 0.6$ & $11.0 \pm 0.8$ & $8.7 \pm 0.9$ & $10.5 \pm 0.7$ \\
\hline NAA & $8.1 \pm 0.9$ & $8.0 \pm 1.0$ & $7.8 \pm 0.9$ & $7.7 \pm 1.0$ & $8.2 \pm 0.8$ & $9.2 \pm 0.9$ & $8.7 \pm 0.8$ & $7.4 \pm 1.0$ & $7.4 \pm 0.8$ & $7.3 \pm 1.3$ \\
\hline NAAG & $1.5 \pm 0.9$ & $2.7 \pm 1.2$ & $2.6 \pm 1.0$ & $0.7 \pm 0.3$ & $0.5 \pm 0.4$ & $1.4 \pm 0.8$ & $0.8 \pm 0.5$ & $3.6 \pm 0.9$ & $1.3 \pm 0.8$ & $3.2 \pm 1.1$ \\
\hline tCho & $1.78 \pm 0.41$ & $1.68 \pm 0.27$ & $1.64 \pm 0.21$ & $1.38 \pm 0.17$ & $1.10 \pm 0.14$ & $0.88 \pm 0.10$ & $1.30 \pm 0.19$ & $2.21 \pm 0.29$ & $2.19 \pm 0.30$ & $1.81 \pm 0.21$ \\
\hline tCre & $5.7 \pm 0.5$ & $5.7 \pm 0.6$ & $5.5 \pm 0.8$ & $6.4 \pm 0.7$ & $6.5 \pm 0.6$ & $6.9 \pm 0.7$ & $7.0 \pm 0.6$ & $8.7 \pm 1.3$ & $9.0 \pm 0.9$ & $6.8 \pm 0.7$ \\
\hline $\mathrm{mI}$ & $3.8 \pm 0.9$ & $3.1 \pm 0.6$ & $4.1 \pm 0.8$ & $4.3 \pm 0.9$ & $4.3 \pm 0.7$ & $4.1 \pm 0.6$ & $4.7 \pm 0.6$ & $5.8 \pm 1.1$ & $5.6 \pm 1.1$ & $3.6 \pm 0.9$ \\
\hline Glu & $7.0 \pm 2.6$ & $6.7 \pm 1.8$ & $6.0 \pm 1.2$ & $8.5 \pm 1.0$ & $8.2 \pm 1.1$ & $8.6 \pm 1.1$ & $8.8 \pm 0.8$ & $7.7 \pm 2.5$ & $7.5 \pm 1.4$ & $6.9 \pm 2.2$ \\
\hline Gln & $1.8 \pm 1.6$ & $1.5 \pm 1.3$ & $2.2 \pm 1.6$ & $4.4 \pm 1.4$ & $3.8 \pm 1.4$ & $3.9 \pm 1.1$ & $4.9 \pm 1.6$ & $4.3 \pm 2.5$ & $5.4 \pm 2.2$ & $2.9 \pm 1.9$ \\
\hline Glx & $8.8 \pm 3.1$ & $8.2 \pm 2.2$ & $8.2 \pm 2.0$ & $12.9 \pm 1.7$ & $12.0 \pm 1.8$ & $12.5 \pm 1.6$ & $13.7 \pm 1.8$ & $12.0 \pm 3.5$ & $12.9 \pm 2.6$ & $9.8 \pm 2.9$ \\
\hline $\mathrm{tNAA}^{*}$ & $9.9 \pm 1.1$ & $10.9 \pm 0.8$ & $10.8 \pm 1.0$ & $9.1 \pm 1.1$ & $9.5 \pm 0.9$ & $11.6 \pm 0.9$ & - & - & - & - \\
\hline $\mathrm{NAA}^{*}$ & $8.4 \pm 0.9$ & $8.2 \pm 1.0$ & $8.0 \pm 1.0$ & $8.4 \pm 1.1$ & $8.9 \pm 0.9$ & $10.1 \pm 1.0$ & - & - & - & - \\
\hline $\mathrm{NAAG}^{*}$ & $1.5 \pm 0.9$ & $2.7 \pm 1.2$ & $2.7 \pm 1.0$ & $0.7 \pm 0.4$ & $0.6 \pm 0.5$ & $1.5 \pm 0.9$ & - & - & - & - \\
\hline
\end{tabular}

Absolute concentrations of metabolites (in mmol/l, mean \pm SD) were related to the water signal and not corrected for the residual $\mathrm{T}_{2}$ relaxation ( $\mathrm{TE}=20 \mathrm{~ms}$ ) and the contributions of CSF to the measured voxel. Glx values and standard deviations were calculated from the data of Glu and Gln for easier comparison with Table 2. Metabolites ${ }^{*}$ ) were corrected for CSF contribution and their $\mathrm{T}_{2}$ relaxation time to illustrate the magnitude of such correction. CSF, cerebrospinal fluid. 
lower in the grey matter, generally less than $1 \mathrm{mmol} / \mathrm{l}$, except for the occipital cortex where it is $1.5 \mathrm{mmol} / \mathrm{l}$. In grey and white matter, NAAG concentration increases in the caudal direction i.e. from the frontal to the parietal and occipital areas (Pouwels and Frahm 1997).

Therefore, it seems that the MR signal of NAA is proportional to the density of neurons in healthy grey matter. This statement is consistent with the already mentioned immunohistochemical publications, which suggest that NAA in the brain is predominantly found in neurons, axons and dendrites. Therefore, the MR signal of NAA is rightly considered to be a neuronal marker. There are several other facts confirming this conclusion.

All studies of diseases in which there is a loss of neurons or axons (infarctions, brain tumors, multiple sclerosis) confirm, without exception, a decrease in NAA (Barker and Lin 2006). In multiple sclerosis, strong correlations were observed between the values of NAA in the brain and the level of patient impairment, which suggests that higher NAA values are a sign of better neuronal function (De Stefano et al. 2005). After artificial damage to neurons in animals, it has been shown that the NAA level, measured using in vivo MRS, very accurately correlated with three biochemical markers of neuronal activity and also with in vitro NMR-observed NAA concentration (Guimaraes et al. 1995).

In some cases, the decrease of NAA is reversible, which suggests that a low NAA signal also reflects neuronal cell dysfunction, not only their permanent damage. Such an increase of NAA is sometimes spontaneous; in other cases, it is in response to therapy. This phenomenon was observed in multiple sclerosis, AIDS, mitochondrial diseases, temporal lobe epilepsy, amyotrophic lateral sclerosis (Barker and Lin 2006) and acute disseminated encephalomyelitis (Ben Sira et al. 2010).

All these studies clearly demonstrate that NAA is a very convenient marker of neuronal activity. There are, however, a few exceptions to this statement. The first is a group of genetic diseases affecting the metabolism of NAA. In patients with the rare Canavan disease, there is a deficit of aspartoacylase, an enzyme which decomposes NAA to acetate and aspartate. In this case, intracellular NAA reaches very high levels (Dezortova and Hajek 2008), yet this is not an indication of increased neuronal activity. On the other hand, in patients with Alexander disease, the signal of NAA is decreased (Brockmann et al. 2003) to such an extent that, in one particular case, the NAA signal in the spectra of a child's brain cortex was absent altogether. The child was mentally impaired, but still she had some brain activity (Martin et al. 2001).

Another exception was suggested by some in vitro studies on isolated tissue cultures, in which NAA was also confirmed in isolated oligodendrocytes (Bhakoo and Pearce 2000) and in a culture of mast cells (Burlina et al. 1997). Therefore, it is clear that a measurable MR signal of NAA is not localized exclusively in the neurons. However, it is not known how much the presence of NAA in cells other than neuronal in vivo contributes to the total NAA signal from the given location in the tissue, or how much this can affect its MRS signal in different pathological scenarios.

In summary, our current knowledge leads us to conclude that NAA is, overall, a sensitive tool to assess irreversible and temporary neuronal damage.

\section{Choline and choline-containing substances}

The MRS peak of tCho ("total cholines", or choline-containing compounds) (Figure 1e) contains the signals of glycerophosphocholine (GPC), phosphocholine (PC) and a small amount of the choline itself. In an MR spectrum, such peaks are distinct only in high-resolution, in vitro MRS of a brain extract. (Barker et al. 1994a). Under the conditions of clinical measurements, these peaks are indistinguishable and manifest only by a deformed shape of a single tCho peak. The tCho signal (3.21 ppm) comes from the protons of the trimethyl amine moiety $\left(-\mathrm{N} \pm\left(\mathrm{CH}_{3}\right)_{3}\right)$ group (De Graaf 2007).

In one molecule of GPC, PC and choline, nine protons of the trimethyl amine group resonate at the frequency of $3.21 \mathrm{ppm}$. This is different to NAA and creatine, in which only three protons of the methyl group $\mathrm{CH}_{3}$ contribute to the MR signal. Therefore, if the peaks of tCho and tCre in a spectrum have the same areas, it means that the molar concentration of tCre is three times higher than the concentration of tCho.

The main metabolites contributing to the tCho signal, PC and GPC, are involved in the metabolism of membrane lipids phosphatidylcholine and sphingomyelin, respectively. However, the latter two are not visible in an in vivo MR spectrum, since choline in the membrane phospholipids is bound, not free to move in the solution (Klein 2000).

Phosphatidylcholine and sphingomyelin are being constantly synthesized and broken down. Since PC and GPC are involved in their metabolic pathways, the signal of tCho and the content of choline-containing phospholipids should correlate under physiological conditions. For example, a higher tCho signal in the white matter compared to cortical grey matter can be partly explained by the fact that white matter contains more myelin and, therefore, more membrane lipids than grey matter (15.6\% compared to $5.9 \%$ of the wet mass). However, we cannot say that there would be a direct proportionality under all conditions, since the membrane-forming mechanism is also governed by other processes (Sastry 1985; Agranoff and Hajra 1994).

Macroscopic distribution of the tCho signal in the healthy brain is very variable compared to other MRS-visible me- 
tabolites (Tables 1 and 2). In healthy subjects, significant differences have been found between cortical grey and white matter, the thalamus and the cerebellum in increasing order. Cortical grey matter contains the lowest concentrations, while cerebellar values are 2 to 2.5 times higher. As well as the variations that exist between different brain structures, a strong gradient, decreasing in the caudal direction, was observed in cortical grey matter (Kreis et al. 1993; Michaelis et al. 1993). This result correlated to post mortem brain studies, in which choline concentrations were found to be $12.8,10.5$ and $7.8 \mathrm{nmol}$ per one $\mathrm{mg}$ of proteins in the frontal, parietal and occipital brain cortex, respectively (Nitsch et al. 1993).

Studies on cell cultures have shown that tCho concentration in glial cells is much higher than in neurons (Urenjak et al. 1993). Moreover, the relationships between MR-visible choline metabolites (PC, GPC and free choline) and membrane phospholipids suggest that the tCho signal should increase, not only during the processes of membrane degradation, but also during their increased production. A typical example of this is a cancerous process (Gill et al. 1990). An increase of tCho corresponds to the degree of malignity of the tumors (except in the necrotic areas, where tCho is not increased). This was confirmed in prostate, breast, liver, head and neck cancers and in other tumors (Barker and Lin 2006; Canese et al. 2009). However, the latest studies in this field suggest that tCho concentration is better correlated to the tumor cell density than to the proliferation index (Yue et al. 2009). It seems the changes of PC and GPC in tumors have certain clinical relevance (Gillies and Morse 2005); however, this phenomenon can hardly be studied using the in vivo proton MRS, since GPC and PC are not separable here.

Active demyelination is one of the processes that causes an increase in the MR signal of tCho (Davie et al. 1993). This increase might be due to the degradation of myelin phospholipids to GPC, or as a result of inflammation (Brenner et al. 1993). Some scientific groups have shown that the tCho peak increases at HIV-associated dementia (Meyerhoff et al. 1999). On the other hand, no significant changes of tCho have been observed with Parkinson disease (Holshouser et al. 1995). A decrease of tCho was found in basal ganglia of patients with depression (Renshaw et al. 1997; Yildiz-Yesiloglu and Ankerst 2006) and in hepatic encephalopathy, where this phenomenon is probably caused by altered transport conditions of choline to the brain (Long et al. 2009).

The influence of ischemia on the MR spectra was studied in animals and humans. In these studies, the tCho peak was increased in the short term, but its signal decreased after several days of global ischemia as a result of lowered GPC concentration (Brulatout et al. 1996). In humans, a decrease of the tCho peak was confirmed 5 months after ischemia (Barker et al. 1994b).

Generally, the tCho signal increases in the majority of pathologic processes; similarly the tNAA signal decreases. Therefore the tNAA:tCho ratio is, in many cases, a suitable coefficient to discriminate healthy and affected brain tissue.

\section{Creatine and phosphocreatine}

The resonance of tCre is also a compound peak composed of two substances, creatine (Cre or $\mathrm{Cr}$ ) and phosphocreatine (PCr), at the frequency of $3.03 \mathrm{ppm}$. tCre has a second strong resonance at $3.91 \mathrm{ppm}$, but it is usually not taken into consideration since it might be ambiguously decreased as a result of strong water suppression (Figure 1f).

Creatine is phosphorylated by creatine kinase to form phosphocreatine, which plays an important role in the storage of energy. It can be utilized for ATP creation from ADP without oxygen consumption.

It has been found in vitro that glial cells contain two to four times more tCre than neurons (Urenjak et al. 1993), similarly to tCho.

Macroscopic tCre distribution in the brain is less variable than the concentration of tCho (Tables 1 and 2). Several studies have shown that its concentration is still higher in cortical grey matter compared to white matter (Kreis et al.

Table 2. Local concentrations of metabolites in a healthy human brain using proton MRS at 3.0 T (data from Baker et al. 2008)

\begin{tabular}{|c|c|c|c|c|c|c|c|c|c|}
\hline & \multicolumn{3}{|c|}{ White matter } & \multicolumn{3}{|c|}{ Grey matter } & \multirow[b]{2}{*}{ Thalamus } & \multirow[b]{2}{*}{ Pons } & \multirow[b]{2}{*}{$\begin{array}{l}\text { Inferior } \\
\text { vermis }\end{array}$} \\
\hline & $\begin{array}{c}\text { Frontal } \\
\text { area }\end{array}$ & $\begin{array}{c}\text { Semioval } \\
\text { center }\end{array}$ & $\begin{array}{l}\text { Parieto- } \\
\text { occipital }\end{array}$ & $\begin{array}{c}\text { Frontal } \\
\text { area }\end{array}$ & $\begin{array}{c}\text { Parietal } \\
\text { area }\end{array}$ & $\begin{array}{c}\text { Occipital } \\
\text { area }\end{array}$ & & & \\
\hline $\mathrm{tNAA}^{*}$ & $11.28 \pm 1.14$ & $12.13 \pm 0.78$ & $10.97 \pm 1.19$ & $11.80 \pm 1.42$ & $11.86 \pm 0.92$ & $13.23 \pm 1.13$ & $13.56 \pm 0.71$ & $12.91 \pm 1.99$ & $11.08 \pm 1.02$ \\
\hline $\mathrm{tCho}^{*}$ & $2.03 \pm 0.39$ & $1.65 \pm 0.25$ & $1.60 \pm 0.24$ & $1.78 \pm 0.59$ & $1.35 \pm 0.16$ & $1.02 \pm 0.09$ & & $2.65 \pm 0.44$ & $2.10 \pm 0.37$ \\
\hline $\mathrm{tCre}^{*}$ & $7.21 \pm 1.06$ & $6.69 \pm 0.37$ & $6.14 \pm 0.92$ & $8.35 \pm 1.22$ & $8.95 \pm 1.13$ & $9.31 \pm 0.86$ & $9.22 \pm 1.16$ & $6.77 \pm 1.48$ & $11.98 \pm 1.02$ \\
\hline $\mathrm{mI}$ & $3.74 \pm 0.65$ & $2.89 \pm 0.41$ & $3.30 \pm 0.60$ & $4.40 \pm 0.92$ & $4.30 \pm 0.79$ & $4.77 \pm 0.64$ & $3.53 \pm 0.52$ & $4.80 \pm 1.45$ & $4.22 \pm 0.91$ \\
\hline Glx & $8.39 \pm 2.02$ & $6.77 \pm 1.90$ & $6.48 \pm 1.58$ & $11.77 \pm 1.92$ & $12.2 \pm 2.66$ & $10.86 \pm 1.81$ & $10.33 \pm 1.40$ & $9.86 \pm 3.52$ & $12.89 \pm 2.99$ \\
\hline
\end{tabular}

Concentrations of metabolites (in $\mathrm{mmol} / \mathrm{l}$; mean $\pm \mathrm{SD}$ ), were corrected to the contribution of CSF. Metabolites $\left({ }^{\star}\right.$ ) were corrected for CSF contribution and their $\mathrm{T}_{2}$ relaxation time. Both corrections lead to an increase in the calculated values, which partly explains some differences to Table 1. CSF, cerebrospinal fluid. 
1993; Michaelis et al. 1993). Another study (Pouwels and Frahm 1998) mentioned the following order of brain structures according to their tCre concentrations (calculated from MRS measurements): cortical white matter (5.5 to $5.7 \mathrm{mM}$ ), cortical grey matter (6.4 to $7.0 \mathrm{mM}$ ), cerebellum (8.7 to 9.0 $\mathrm{mM})$. Concentration in the thalamus $(6.8 \mathrm{mM})$ was similar to the concentration in the cortical grey matter.

It is often mentioned in the literature that the tCre signal is not changed significantly in most pathological states, and some works take this as a suitable standard to compare the changes in other signals. However, tCre is sensitive to changes in brain energy processes; it decreases with decreased metabolism. These changes are observable in trauma and hypoxia. In many tumors, the tCre signal is also decreased or absent (Castillo et al. 1996; Burtscher and Holtas 2001).

Further, there is a rare condition of absent brain creatine, which is a consequence of its disturbed synthesis in the liver (GAMT deficiency) (Stockler et al. 1994). There are other cases of impaired creatine transport to the brain (Cecil et al. 2001). Since creatine is synthesized in the liver, its brain concentration would decrease during liver damage (Barker and Lin 2006).

Dechent et al. (1999) found that the tCre signal in the brain changes under long-term oral administration of creatine tablets (4 times a week). The most prominent changes were found in the thalamus (an increase of 15\%), then, in decreasing order, in white matter, in the cerebellum and in grey matter. The changes in the spectra were fully reversible, which was confirmed by repeated measurements taken three months after ending creatine administration.

\section{Myo-inositol}

The myo-inositol (mI) peak is present in the region of 3.5 to $3.6 \mathrm{ppm}$; its second multiplet is positioned at $4.06 \mathrm{ppm}$ (Figure 1g). In accordance with the multiplet structure of the $\mathrm{mI}$ signal and its short relaxation time, $\mathrm{T}_{2}$, the $\mathrm{mI}$ signal is visible only in the spectra with short TE.

Myo-inositol is a pentose sugar, which takes part in the metabolism of inositol phospholipids built in membranes. It is an important brain metabolite (Pouwels and Frahm 1998).

According to the studies performed on specific cell structures, $\mathrm{mI}$ is a marker of the glia, since it is not present in neurons (Brand et al. 1993). Details about spatial distribution of $\mathrm{mI}$ in the brain can be found in Table 1 and 2 . The concentration of $\mathrm{mI}$ is lowest in grey matter and highest in the cerebellum, which is the same pattern as for tCre and tCho (Pouwels and Frahm 1998).

Since $\mathrm{mI}$ is involved in many biochemical processes, there is no single reason for its uneven distribution in the brain. High values of $\mathrm{mI}$ (and tCho) in the cerebellum might be a consequence of higher activity of glial cells or higher membrane density in this area (Pouwels and Frahm 1998). During experimental measurements in animal cerebellum after artificially initiated hypernatremia, the $\mathrm{mI}$ signal was notably increased, which suggests that cerebellar osmoregulation extensively uses $\mathrm{mI}$ as an osmolyte. Also, increased expression of mRNA for sodium/myo-inositol co-transporter (SMIT) was observed during hypernatremia, especially in the cerebellar region (Minami et al. 1996). This co-transporter plays a role in redistribution of intracellular and extracellular $\mathrm{mI}$ during changes of cerebellar osmolality (Pouwels and Frahm 1998). This process is very important in the cerebellum due to an increased presence of glial cells, mostly astrocytes, for which SMIT is probably the most important intracellular osmoregulator (Strange et al. 1994).

Decreased values of $\mathrm{mI}$ were found in hepatic encephalopathy, and the degree of damage correlated with the decrease of the $\mathrm{mI}$ signal. A decrease of $\mathrm{mI}$ was so significant in patients during hypoosmolarity that its signal was barely observable. After correcting for osmolarity, the level of $\mathrm{mI}$ returned to its original value (Haussinger et al. 1994). An increase of $\mathrm{mI}$ was also found at bipolar disorder (Frey et al. 2005, 2007).

The myo-inositol signal increases in patients with Alzheimer disease and this acts as a specific marker, distinguishing the illness from other types of dementia (Kantarci 2007). Its signal also increases in demyelination diseases (Kruse et al. 1993). The exact pathophysiological cause of these changes is not known. The most probable hypothesis suggests an increased number of glial cells which contain higher amounts of mI (Brand et al. 1993).

The signal of $\mathrm{mI}$ is present almost at the same frequency as glycine. However, glycine resonates as a singlet (single peak). In the healthy brain, glycine is only present in very low concentrations, but it can be increased to a detectable level in some diseases, such as non-ketotic hyperglycinemia (Barker and Lin 2006) or cancer (Righi et al. 2010).

\section{Glutamate and glutamine}

Glutamate (Glu) and glutamine (Gln) are the key compounds of brain metabolism. Since their peaks mutually overlap, we are generally not able to separate them at a 1.5 T magnetic field and thus we quantify their combined signal in the area of 2.1 to $2.4 \mathrm{ppm}$. In MRS, this total signal is labeled Glx. Multiplets of protons from the ${ }^{3} \mathrm{CH}_{2}$ and ${ }^{4} \mathrm{CH}_{2}$ groups resonate between 2.1 and $2.4 \mathrm{ppm}$ and protons from the ${ }^{2} \mathrm{CH}_{2}$ group resonate at $3.7 \mathrm{ppm}$ (Figure 1h-i). At $3 \mathrm{~T}$ magnetic fields, these metabolites can be quite reliably separated using a proper pulse sequence and an appropriate spectral fitting technique (Provencher 1993; Srinivasan et al. 2005). At $4 \mathrm{~T}$ magnetic fields or higher, the resonances of the ${ }^{4} \mathrm{CH}_{2}$ groups in glutamate and glutamine 


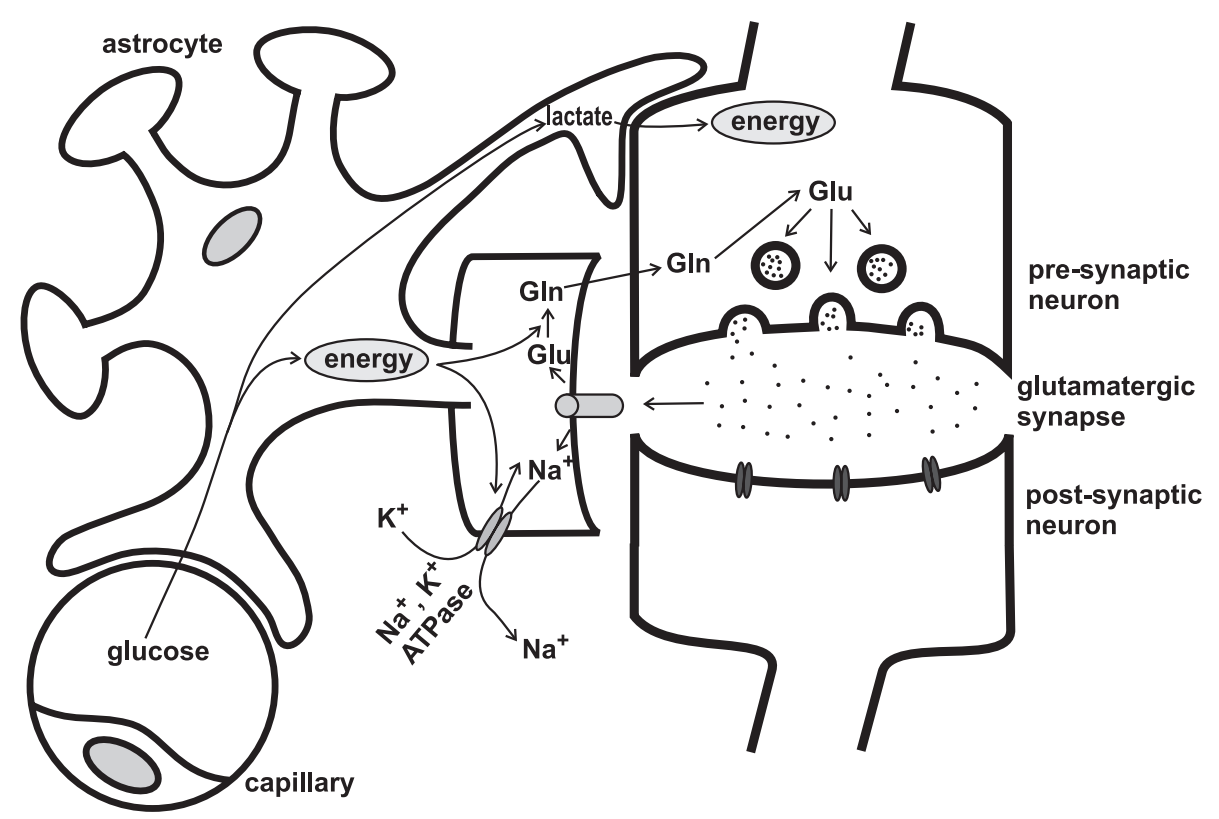

Figure 3: Mechanisms of synaptic activity related to glutamate (scheme was created according to Magistretti et al. 1999). Glutamate (Glu) excreted in the neuron diffuses through the synaptic gap and is recognized by the receptors of the post-synaptic neuron. The released glutamate must be promptly removed from the synaptic gap so that the synapse will be ready for the next excitation. This is primarily provided by a highly effective recapturing system in the astrocytes that surround each glutamatergic synapse. Glutamate is absorbed by astrocytes using specific transporters, which use the electrochemical gradient of $\mathrm{Na}^{+}$as their motive force. The astrocyte then has a double role: i) it has to get rid of the absorbed glutamate, and ii) renew the original gradient of $\mathrm{Na}^{+}$. The sodium gradient is renewed by membrane $\mathrm{Na}^{+}, \mathrm{K}^{+}$-ATPases and glutamate is converted in astrocytes to glutamine $(\mathrm{Gln})$ in a reaction catalyzed by glutamine synthetase. Glutamine is then released from astrocytes and captured by excitatory neurons. In the neuronal cell, glutamine is enzymatically converted to glutamate, which is consequently added to the glutamate deposit, ready for excitatory signalization. Glutamine synthesis and $\mathrm{Na}^{+}, \mathrm{K}^{+}$-ATPase reaction consumes energy in the form of ATP. Since ATP exchange mechanism between astrocytes and neurons is still unknown, every cell uses its own energy management (Magistretti et al. 1999). This process is energetically so demanding that it is responsible for $80-90 \%$ of the total cortical glucose consumption (Sibson et al. 1998).

are well separated and can be reliably determined (Mekle et al. 2009).

Glutamate is the most abundant amino acid in the brain and the most important neurotransmitter. Up to $90 \%$ of neurons excrete glutamate during their excitation. Metabolic pathways of glutamate and glutamine are explained in Figure 3.

Spatial distribution of glutamate and glutamine in the brain measured at a $3 \mathrm{~T}$ magnetic field (Baker et al. 2008) is shown in Table 2. Even though it was possible to distinguish between glutamate and glutamine at $3 \mathrm{~T}$, the work suggested that it was still more precise to mention the summary value of Glx. The results may be compared to a much earlier measurement (Table 1). According to Baker et al. (2008), the concentration of Glx (calculated from MRS) in the brain reaches values from $6.5 \mathrm{mmol} / \mathrm{l}$ in parietal and occipital white matter to $12.9 \mathrm{mmol} / \mathrm{l}$ in the lower part of the vermis.

The authors also found that the values of Glx in white matter are significantly higher than in grey matter. However, they found no statistically significant variations along the white or grey matter itself (Baker et al. 2008).

Due to difficult separation of both metabolites at 1.5 T magnetic fields, there are not many studies which would observe pathological conditions linked to the changes of these substances. Not a long time ago it was shown that the signal of glutamate increased in the plaques of multiple sclerosis (Srinivasan et al. 2005). Later studies at 1.5 T found an increased signal of glutamine in patients with liver failure in hepatic encephalopathy (probably as a result of an increased level of blood ammonia, which increased the synthesis of glutamine (Barker and Lin 2006), and in patients with Reye syndrome (Kreis et al. 1995).

\section{Post-processing and interpretation of MRS data}

Correct spectral evaluation and interpretation is as sensitive and important a process as proper experimental acquisition of the data. As seen in our sample spectrum with short TE 
(Figure 1a, c-i), it is not always an easy task to correctly select an area belonging to a chosen peak. Due to complexity of the signals of many metabolites, manual selection of the peak areas and setting of a correct phase of the spectrum also introduces some subjective influence. Both of these drawbacks are robustly eliminated by using established and automated evaluation algorithms, such as the LCModel and MRUI (Provencher 1993; van den Boogaart 1997). Many works show that accurate scientific manual evaluation brings similar results to automated evaluation (Jiru et al. 2003).

However, sophisticated data evaluation routines are not supplied as a component of the scanner operation software. At this stage of development, MRS measurement and data processing in most brain areas usually require at least initial setting by a skilled physicist. We believe that, in the future, the manufacturers of clinical scanners will take this into account, so that the accuracy of clinical spectroscopic examinations will be increased.

\section{Current trends in proton MRS}

Further development in the accuracy and range of applications of MRS is taking place in several areas. Technological progress allowing movement to higher magnetic fields results in higher sensitivity and increased spectral resolution, thus enabling identification of new metabolites and more precise quantification of the ones known from lower fields. However, several technological challenges have to be solved at higher fields (Ugurbil et al. 2003). The development of new hardware takes place in the field of radiofrequency coils (Fujita 2007) and shimming (Juchem et al. 2010). New advances in the pulse sequences push the usage of MRS and MRI to applications previously considered impossible (Zhang et al. 2010). Implementation of proper data processing, including correct absolute quantification, also brings more accuracy to the results measured by MRS.

Acknowledgements. This work was supported by the projects "Creating a new diagnostic algorithm for selected cancer diseases" and "Center of excellence for research in personalized therapy (CEVYPET)", code: 26220120053, co-financed from EU sources and the European Regional Development Fund; and by the grant of the Slovak Ministry of Health, No. 2007/57-UK-17.

\section{References}

Agranoff B. W., Hajra A. K. (1994): Lipids. Raven Press, New York Barker P. B., Breiter S. N., Soher B. J., Chatham J. C., Forder J. R., Samphilipo M. A., Magee C. A., Anderson J. H. (1994a): Quantitative proton spectroscopy of canine brain: In vivo and in vitro correlations. Magn. Reson. Med. 32, 157-163 http://dx.doi.org/10.1002/mrm.1910320202
Barker P. B., Gillard J. H., Van Zijl P. C. M., Soher B. J., Hanley D. F., Agildere A. M., Oppenheimer S. M., Bryan R. N. (1994b): Acute stroke: Evaluation with serial proton MR spectroscopic imaging. Radiology 192, 723-732

Barker P. B., Lin D. D. M. (2006): In vivo proton MR spectroscopy of the human brain. Prog. Nucl. Mag. Res. Sp. 49, 99-128 http://dx.doi.org/10.1016/j.pnmrs.2006.06.002

Baker E. H., Basso G., Barker P. B., Smith M. A., Bonekamp D., Horska A. (2008): Regional apparent metabolite concentrations in young adult brain measured by (1)H MR spectroscopy at 3 Tesla. J. Magn. Reson. Imaging 27, 489-499 http://dx.doi.org/10.1002/jmri.21285

Baslow M. H. (2000): Functions of N-acetyl-L-aspartate and N-acetyl-L-aspartylglutamate in the vertebrate brain: Role in glial cell-specific signaling. J. Neurochem. 75, 453-459 http://dx.doi.org/10.1046/j.1471-4159.2000.0750453.x

Ben Sira L., Miller E., Artzi M., Fattal-Valevski A., Constantini S., Ben Bashat D. (2010): 1H-MRS for the diagnosis of acute disseminated encephalomyelitis: insight into the acute-disease stage. Pediatr. Radiol. 40, 106-113 http://dx.doi.org/10.1007/s00247-009-1372-9

Benarroch E. E. (2008): N-Acetylaspartate and N-acetylaspartylglutamate: Neurobiology and clinical significance. Neurology 70, 1353-1357 http://dx.doi.org/10.1212/01.wnl.0000311267.63292.6c

Bhakoo K. K., Pearce D. (2000): In vitro expression of N-acetyl aspartate by oligodendrocytes: Implications for proton magnetic resonance spectroscopy signal in vivo. J. Neurochem. 74, 254-262 http://dx.doi.org/10.1046/j.1471-4159.2000.0740254.x

Brand A., Richter-Landsberg C., Leibfritz D. (1993): Multinuclear NMR studies on the energy metabolism of glial and neuronal cells. Dev. Neurosci. (Basel) 15, 289-298 http://dx.doi.org/10.1159/000111347

Brenner R. E., Munro P. M. G., Williams S. C. R., Bell J. D., Barker G. J., Hawkins C. P., Landon D. N., McDonald W. I. (1993): The proton NMR spectrum in acute EAE: The significance of the change in the Cho:Cr ratio. Magn. Reson. Med. 29, 737-745 http://dx.doi.org/10.1002/mrm.1910290605

Brockmann K., Dechent P., Meins M., Haupt M., Sperner J., Stephani U., Frahm J., Hanefeld F. (2003): Cerebral proton magnetic resonance spectroscopy in infantile Alexander disease. J. Neurol. 250, 300-306 http://dx.doi.org/10.1007/s00415-003-0995-2

Brulatout S., Meric P., Loubinoux I., Borredon J., Correze J. L., Roucher P., Gillet B., Berenger G., Beloeil J. C., Tiffon B., Mispelter J., Seylaz J. (1996): A one-dimensional (proton and phosphorus) and two-dimensional (proton) in vivo NMR spectroscopic study of reversible global cerebral ischemia. J. Neurochem. 66, 2491-2499 http://dx.doi.org/10.1046/j.1471-4159.1996.66062491.x

Burlina A. P., Ferrari V., Facci L., Skaper S. D., Burlina A. B. (1997): Mast cells contain large quantities of secretagogue-sensitive $\mathrm{N}$ - acetylaspartate. J. Neurochem. 69, 1314-1317 http://dx.doi.org/10.1046/j.1471-4159.1997.69031314.x

Burtscher I. M., Holtas S. (2001): Proton MR spectroscopy in clinical routine. J. Magn. Reson. Imaging 13, 560-567 http://dx.doi.org/10.1002/jmri.1079 
Canese R., Iorio E., Ricci A., Pisanu M. E., Giannini M., Podo F. (2009): Metabolite quantification in tumours by magnetic resonance spectroscopy: Objectives, results and perspectives. Curr. Med. Imaging Rev. 5, 110-127 http://dx.doi.org/10.2174/157340509788185306

Castillo M., Kwock L., Mukherji S. K. (1996): Clinical applications of proton MR spectroscopy. Am. J. Neuroradiol. 17, 1-15

Cecil K. M., Salomons G. S., Ball Jr. W. S., Wong B., Chuck G., Verhoeven N. M., Jakobs C., Degrauw T. J. (2001): Irreversible brain creatine deficiency with elevated serum and urine creatine: A creatine transporter defect? Ann. Neurol. 49, 401-404 http://dx.doi.org/10.1002/ana.79

Chance B., Nakase Y., Bond M. (1978): Detection of 31P nuclear magnetic resonance signals in brain by in vivo and freeze-trapped assays. Proc. Natl. Acad. Sci. U.S.A. 75, 4925-4929 http://dx.doi.org/10.1073/pnas.75.10.4925

Davie C. A., Hawkins C. P., Barker G. J., Brennan A., Tofts P. S., Miller D. H., McDonald W. I. (1993): Detection of myelin breakdown products by proton magnetic resonance spectroscopy. Lancet 341, 630-631 http://dx.doi.org/10.1016/0140-6736(93)90390-3

De Graaf R. A. (2007): In Vivo NMR Spectroscopy. John Wiley \& sons, Chichester, UK http://dx.doi.org/10.1002/9780470512968

De Stefano N., Bartolozzi M. L., Guidi L., Stromillo M. L., Federico A. (2005): Magnetic resonance spectroscopy as a measure of brain damage in multiple sclerosis. J. Neurol. Sci. 233, 203-208 http://dx.doi.org/10.1016/j.jns.2005.03.018

Dechent P., Pouwels P. J. W., Wilken B., Hanefeld F., Frahm J. (1999): Increase of total creatine in human brain after oral supplementation of creatine-monohydrate. A localized proton MR spectroscopy study. Am. J. Physiol. 277, R698-704

Dezortova M., Hajek M. (2008): (1)H MR spectroscopy in pediatrics. Eur. J. Radiol. 67, 240-249

http://dx.doi.org/10.1016/j.ejrad.2008.02.035 PMid: 18423936

Frahm J., Michaelis T., Merboldt K. D., Hanicke W., Gyngell M. L., Bruhn H. (1991): On the N-acetyl methyl resonance in localized H-1-NMR spectra of human brain in vivo. NMR Biomed. 4, 201-204 http://dx.doi.org/10.1002/nbm.1940040408

Frey B. N., Folgierini M., Nicoletti M., Machado-Vieira R., Stanley J. A., Soares J. C., Kapczinski F. (2005): A proton magnetic resonance spectroscopy investigation of the dorsolateral prefrontal cortex in acute mania. Hum. Psychopharmacol. 20, 133-139 http://dx.doi.org/10.1002/hup.671

Frey B. N., Stanley J. A., Nery F. G., Monkul E. S., Nicoletti M. A., Chen H. H., Hatch J. P., Caetano S. C., Ortiz O., Kapczinski F., Soares J. C. (2007): Abnormal cellular energy and phospholipid metabolism in the left dorsolateral prefrontal cortex of medication-free individuals with bipolar disorder: an in vivo $1 \mathrm{H}$ MRS study. Bipolar Disord. 9 (Suppl. 1), 119-127 http://dx.doi.org/10.1111/j.1399-5618.2007.00454.x

Fujita H. (2007): New horizons in MR technology: RF coil designs and trends. Magn. Reson. Med. Sci. 6, 29-42 http://dx.doi.org/10.2463/mrms.6.29

Gill S. S., Thomas D. G. T., Van Bruggen N., Gadian D. G., Peden C. J., Bell J. D., Cox I. J., Menon D. K., Iles R. A., Bryant D. J.,
Coutts G. A. (1990): Proton MR spectroscopy of intracranial tumours: In vivo and in vitro studies. J. Comput. Assist. Tomo. 14, 497-504 http://dx.doi.org/10.1097/00004728-199007000-00001

Gillies R. J., Morse D. L. (2005): In vivo magnetic resonance spectroscopy in cancer. Annu. Rev. Biomed. Eng. 7, 287-326 http://dx.doi.org/10.1146/annurev.bioeng.7.060804.100411

Guimaraes A. R., Schwartz P., Prakash M. R., Carr C. A., Berger U. V., Jenkins B. G., Coyle J. T., Gonzalez R. G. (1995): Quantitative in vivo $1 \mathrm{H}$ nuclear magnetic resonance spectroscopic imaging of neuronal loss in rat brain. Neuroscience 69, 1095-1101 http://dx.doi.org/10.1016/0306-4522(95)00300-8

Haussinger D., Laubenberger J., vom Dahl S., Ernst T., Bayer S., Langer M., Gerok W., Hennig J. (1994): Proton magnetic resonance spectroscopy studies on human brain myo-inositol in hypo-osmolarity and hepatic encephalopathy. Gastroenterology 107, 1475-1480

Holshouser B. A., Komu M., Moller H. E., Zijlmans J., Kolem H., Hinshaw D. B., Jr., Sonninen P., Vermathen P., Heerschap A., Masur H., et al. (1995): Localized proton NMR spectroscopy in the striatum of patients with idiopathic Parkinson's disease: a multicenter pilot study. Magn. Reson. Med. 33, 589-594 http://dx.doi.org/10.1002/mrm.1910330502

Jiru F., Dezortova M., Burian M., Hajek M. (2003): The role of relaxation time corrections for the evaluation of long and short echo time $1 \mathrm{H}$ MR spectra of the hippocampus by NUMARIS and LCModel techniques. Magn. Reson. Mater. Phy. 16, 135-143 http://dx.doi.org/10.1007/s10334-003-0018-4

Juchem C., Nixon T. W., Diduch P., Rothman D. L., Starewicz P., de Graaf R. A. (2010): Dynamic shimming of the human brain at 7 Tesla. Concepts Magn. Reson. Part B Magn. Reson. Eng. 37, B116-128

Kantarci K. (2007): 1H magnetic resonance spectroscopy in dementia. Br. J. Radiol. 80 (Spec. No. 2), S146-152

Klein J. (2000): Membrane breakdown in acute and chronic neurodegeneration: Focus on choline-containing phospholipids. J. Neural Transm. 107, 1027-1063 http://dx.doi.org/10.1007/s007020070051

Kreis R., Ernst T., Ross B. D. (1993): Absolute quantitation of water and metabolites in the human brain. II. Metabolite concentrations. J. Magn. Reson. 102, 9-19

http://dx.doi.org/10.1006/jmrb.1993.1056

Kreis R., Pfenninger J., Herschkowitz N., Boesch C. (1995): In vivo proton magnetic resonance spectroscopy in a case of Reyes syndrome. Intens. Care Med. 21, 266-269 http://dx.doi.org/10.1007/BF01701487

Kruse B., Hanefeld F., Christen H.-J., Bruhn H., Michaelis T., Hanicke W., Frahm J. (1993): Alterations of brain metabolites in metachromatic leukodystrophy as detected by localized proton magnetic resonance spectroscopy in vivo. J. Neurol. 241, 68-74 http://dx.doi.org/10.1007/BF00869766

Leuba G., Garey L. J. (1989): Comparison of neuronal and glial numerical density in primary and secondary visual cortex of man. Exp. Brain Res. 77, 31-38 http://dx.doi.org/10.1007/BF00250564 
Long L. L., Li X. R., Huang Z. K., Jiang Y. M., Fu S. X., Zheng W. (2009): Relationship between changes in brain MRI and (1)H-MRS, severity of chronic liver damage, and recovery after liver transplantation. Exp. Biol. Med. (Maywood) 234, 1075-1085 http://dx.doi.org/10.3181/0903-RM-118

Magistretti P. J., Pellerin L., Rothman D. L., Shulman R. G. (1999): Energy on demand. Science 283, 496-497 http://dx.doi.org/10.1126/science.283.5401.496

Martin E., Capone A., Schneider J., Hennig J., Thiel T. (2001): Absence of $\mathrm{N}$-acetylaspartate in the human brain: Impact on neurospectroscopy? Ann. Neurol. 49, 518-521 http://dx.doi.org/10.1002/ana.102

Mekle R., Mlynarik V., Gambarota G., Hergt M., Krueger G., Gruetter R. (2009): MR spectroscopy of the human brain with enhanced signal intensity at ultrashort echo times on a clinical platform at 3T and 7T. Magn. Reson. Med. 61, $1279-1285$ http://dx.doi.org/10.1002/mrm.21961

Meyerhoff D. J., Bloomer C., Cardenas V., Norman D., Weiner M. W., Fein G. (1999): Elevated subcortical choline metabolites in cognitively and clinically asymptomatic HIV+ patients. Neurology 52, 995-1003

Michaelis T., Merboldt K.-D., Bruhn H., Hanicke W., Frahm J. (1993): Absolute concentrations of metabolites in the adult human brain in vivo: Quantification of localized proton MR spectra. Radiology 187, 219-227

Minami Y., Inoue K., Shimada S., Morimura H., Miyai A., Yamauchi A., Matsunaga T., Tohyama M. (1996): Rapid and transient up-regulation of $\mathrm{Na}+$ /myo-inositol cotransporter transcription in the brain of acute hypernatremic rats. Mol. Brain Res. 40, 64-70 http://dx.doi.org/10.1016/0169-328X(96)00034-4

Moffett J. R., Namboodiri M. A., Neale J. H. (1993): Enhanced carbodiimide fixation for immunohistochemistry: application to the comparative distributions of $\mathrm{N}$-acetylaspartylglutamate and $\mathrm{N}$-acetylaspartate immunoreactivities in rat brain. J. Histochem. Cytochem. 41, 559-570 http://dx.doi.org/10.1177/41.4.8450195

Moffett J. R., Namboodiri A. M. (2006): Expression of N-acetylaspartate and $\mathrm{N}$-acetylaspartylglutamate in the nervous system. Adv. Exp. Med. Biol. 576, 7-26; discussion 361-363 http://dx.doi.org/10.1007/0-387-30172-0_2

Nitsch R. M., Blusztajn J. K., Doyle F. M., Robitaille Y., Wurtman R. J., Growdon J. H., Kish S. J. (1993): Phospholipid metabolite levels are altered in cerebral cortex of patients with dominantly inherited olivopontocerebellar atrophy. Neurosci. Lett. 161, 191-194 http://dx.doi.org/10.1016/0304-3940(93)90291-R

Pouwels P. J., Frahm J. (1997): Differential distribution of NAA and NAAG in human brain as determined by quantitative localized proton MRS. NMR Biomed. 10, 73-78

http://dx.doi.org/10.1002/(SICI)1099-1492(199704)10:2<73:: AID-NBM448>3.0.CO;2-4

Pouwels P. J. W., Frahm J. (1998): Regional metabolite concentrations in human brain as determined by quantitative localized proton MRS. Magn. Reson. Med. 39, 53-60 http://dx.doi.org/10.1002/mrm.1910390110
Provencher S. W. (1993): Estimation of metabolite concentrations from localized in vivo proton NMR spectra. Magn. Reson. Med. 30, 672-679

http://dx.doi.org/10.1002/mrm.1910300604

Renshaw P. F., Lafer B., Babb S. M., Fava M., Stoll A. L., Christensen J. D., Moore C. M., Yurgelun-Todd D. A., Bonello C. M., Pillay S. S., Rothschild A. J., Nierenberg A. A., Rosenbaum J. F., Cohen B. M. (1997): Basal ganglia choline levels in depression and response to fluoxetine treatment: An in vivo proton magnetic resonance spectroscopy study. Biol. Psychiat. 41, 837-843 http://dx.doi.org/10.1016/S0006-3223(96)00256-9

Righi V., Andronesi O. C., Mintzopoulos D., Black P. M., Tzika A. A. (2010): High-resolution magic angle spinning magnetic resonance spectroscopy detects glycine as a biomarker in brain tumors. Int. J. Oncol. 36, 301-306

Sastry P. S. (1985): Lipids of nervous tissue: composition and metabolism. Prog. Lipid Res. 24, 69-176 http://dx.doi.org/10.1016/0163-7827(85)90011-6

Sibson N. R., Dhankhar A., Mason G. F., Rothman D. L., Behar K. L., Shulman R. G. (1998): Stoichiometric coupling of brain glucose metabolism and glutamatergic neuronal activity. P. Natl. Acad. Sci. USA 95, 316-321 http://dx.doi.org/10.1073/pnas.95.1.316

Simmons M. L., Frondoza C. G., Coyle J. T. (1991): Immunocytochemical localization of $\mathrm{N}$-acetyl-aspartate with monoclonal antibodies. Neuroscience 45, 37-45 http://dx.doi.org/10.1016/0306-4522(91)90101-S

Srinivasan R., Sailasuta N., Hurd R., Nelson S., Pelletier D. (2005): Evidence of elevated glutamate in multiple sclerosis using magnetic resonance spectroscopy at $3 \mathrm{~T}$. Brain 128, 1016-1025 http://dx.doi.org/10.1093/brain/awh467

Stockler S., Holzbach U., Hanefeld F., Marquardt I., Helms G., Requart M., Hanicke W., Frahm J. (1994): Creatine deficiency in the brain: A new, treatable inborn error of metabolism. Pediatr. Res. 36, 409-413 http://dx.doi.org/10.1203/00006450-199409000-00023

Strange K., Emma F., Paredes A., Morrison R. (1994): Osmoregulatory changes in myo-inositol content and $\mathrm{Na}+$ /myo-inositol cotransport in rat cortical astrocytes. GLIA 12, 35-43 http://dx.doi.org/10.1002/glia.440120105

Ugurbil K., Adriany G., Andersen P., Chen W., Garwood M., Gruetter R., Henry P. G., Kim S. G., Lieu H., Tkac I., Vaughan T., Van De Moortele P. F., Yacoub E., Zhu X. H. (2003): Ultrahigh field magnetic resonance imaging and spectroscopy. Magn. Reson. Imaging 21, 1263-1281 http://dx.doi.org/10.1016/j.mri.2003.08.027

Urenjak J., Williams S. R., Gadian D. G., Noble M. (1993): Proton nuclear magnetic resonance spectroscopy unambiguously identifies different neural cell types. J. Neurosci. 13, 981-989

van den Boogaart A. (1997): Mrui Manual V. 96.3. A user's guide to the magnetic resonance user interface software package. Delft Technical University Press, Delft, Netherlands

Yildiz-Yesiloglu A., Ankerst D. P. (2006): Neurochemical alterations of the brain in bipolar disorder and their implications for pathophysiology: a systematic review of the in vivo proton 
magnetic resonance spectroscopy findings. Prog. Neuropsychopharmacol. Biol. Psychiatry 30, 969-995 http://dx.doi.org/10.1016/j.pnpbp.2006.03.012

Yue Q., Shibata Y., Isobe T., Anno I., Kawamura H., Gong Q.-Y., Matsumura A. (2009): Absolute choline concentration measured by quantitative proton MR spectroscopy correlates with cell density in meningioma. Neuroradiology 51, 61-67 http://dx.doi.org/10.1007/s00234-008-0461-z

Zhang S., Block K. T., Frahm J. (2010): Magnetic resonance imaging in real time: advances using radial FLASH. J. Magn. Reson. Imaging 31, 101-109

http://dx.doi.org/10.1002/jmri.21987

Received: December 12, 2010

Final version accepted: June 13, 2011 